\title{
Palladium(0)-Catalyzed Difunctionalization of 1,3-Dienes: From Racemic to Enantioselective
}

\author{
Xiang $\mathbf{W u}^{\mathrm{a}}$ \\ Liu-Zhu Gong*b,c (i) \\ a Anhui Province Key Laboratory of Advanced Catalytic \\ Materials and Reaction Engineering, School of Chemistry and Chemical \\ Engineering, Hefei University of Technology, Hefei 230009, P. R. of China \\ ${ }^{b}$ Department of Chemistry, University of Science and Technology of \\ China, Hefei 230026, P. R. of China \\ Collaborative Innovation Center of Chemical Science and Engineering, \\ Tianjin 300072, P. R. of China \\ gonglz@ustc.edu.cn \\ Published as part of the 50 Years SYNTHESIS - Golden Anniversary Issue
}

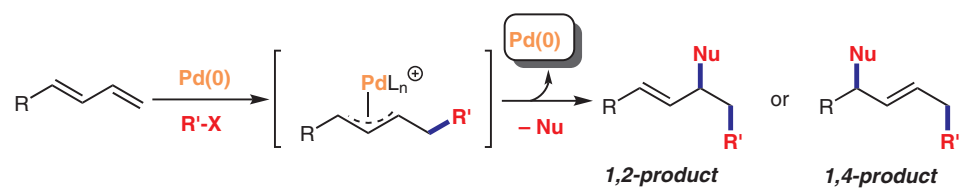

$\mathrm{X}=\mathrm{Br}$, I, OTf, ONf, N, $\mathrm{N}_{2}^{+}$

$\mathrm{Nu}=\mathrm{N}, \mathrm{B}, \mathrm{C}, \mathrm{H}, \mathrm{O}, \mathrm{Si}$
Received: 17.10.2018

Accepted after revision: 18.10 .2018

Published online: 15.11 .2018

DOI: 10.1055/s-0037-1610379; Art ID: ss-2018-z0700-sr

License terms: CCO

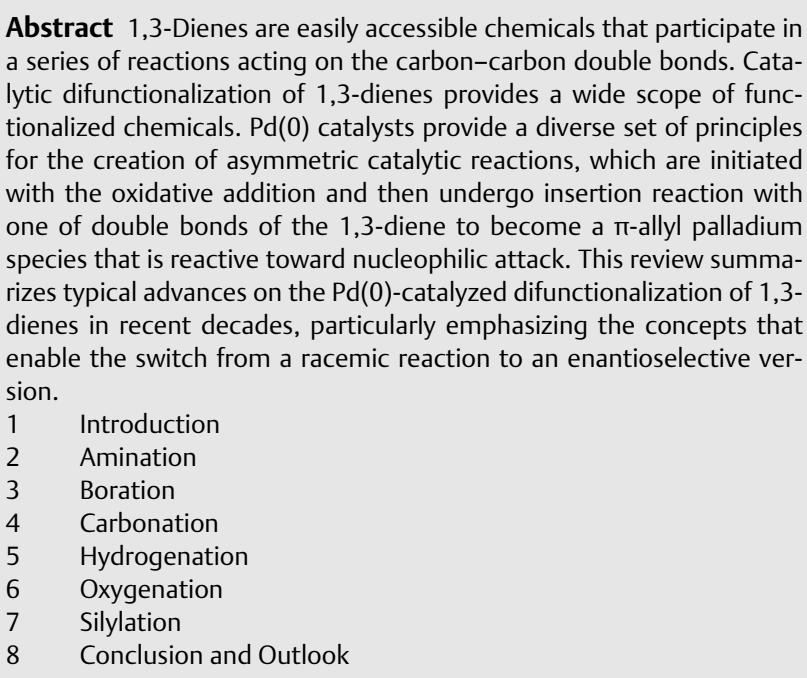

Key words palladium(0), asymmetric catalysis, difunctionalization, 1,3-dienes, cascade reaction

\section{Introduction}

Buta-1,3-diene, which is important industrially as a monomer in the production of synthetic rubber, is produced from steam crackers on a scale of more than 10 million tons per year worldwide. ${ }^{1}$ The last several decades have witnessed the proliferation of fundamentally important and synthetically significant methods by functionalizing 1,3-diene and its derivatives, ${ }^{2}$ which have been prevalently applied in the natural product synthesis, medicinal chemistry and materials science. ${ }^{3}$ The difunctionalization of $1,3-$ dienes provides a wide spectrum of structurally diverse and

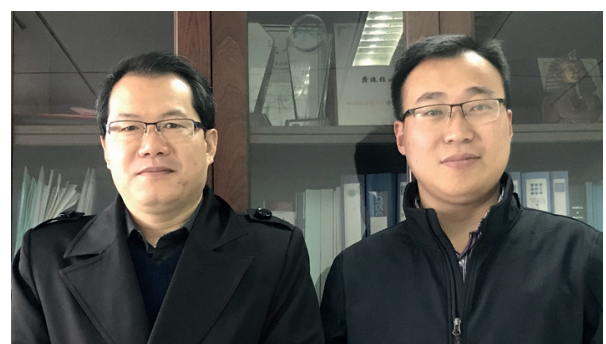

Liu-Zhu Gong (left) was born in October 1970 in Henan, China. He graduated from Henan Normal University (1993) and received his Ph.D. (2000) from the Institute of Chemistry, Chinese Academy of Sciences. He was a visiting scholar (Joint Ph.D. graduate student program) at the University of Virginia and an Alexander von Humboldt Research Fellow at the University of Munich (2003-2004). He was appointed an associate professor of Chengdu Institute of Organic Chemistry, Chinese Academy of Sciences in 2000 and was promoted to a full professor in 2001. Since 2006, he has been a full professor of University of Science and Technology of China. He was appointed the Cheung Kong Scholar Professor of organic chemistry in 2007. His research interests include organo-/transition-metal cooperative and relay catalysis, asymmetric multicomponent and cascade reactions, catalytic asymmetric functionalization of allylic $\mathrm{C}-\mathrm{H}$ bonds, and enantioselective total synthesis of natural products.

Xiang Wu (right) was born in 1982 in Jiangsu, China. He received his B.Sc. degree in chemistry from Nankai University in 2005. He completed his Ph.D. studies in organic chemistry (2005-2010) at the same institution under the supervision of Professor Wei-dong Z. Li. He worked in Suzhou Novartis Pharma Technology Co., Ltd from 2010 to 2012. He was a postdoctoral researcher under the guidance of Professor Liu-Zhu Gong at University of Science and Technology of China (2012-2014) and Professor Gong Chen at the Pennsylvania State University (20142015). Since 2015, he has been an associate professor at Hefei University of Technology and his research interests are in palladium-catalyzed functionalization of dienes and oxidative asymmetric cycloaddition.

densely functionalized chemicals with great potential in organic synthesis, and has hence been considered a powerful strategy in synthetic organic chemistry. ${ }^{4}$ In the difunctionalization of 1,3-dienes, it is a significant challenge to control the regioselectivity toward 1,2- or 1,4-addition because 
of the various coordination and insertion modes conceivable for a transition-metal catalyst. In recent years, with the development of organometallic chemistry, transition-metal catalyst (palladium, copper, nickel and more) enabled difunctionalization of 1,3-dienes has been reported, frequently and continuously. Both $\operatorname{Pd}(0)$ and $\operatorname{Pd}($ II) catalysts are able to promote difunctionalization reaction of carboncarbon double bonds. The palladium(II) coordinated with one of double bonds of 1,3-diene undergoes a nucleopalladation with a nucleophile $\left(\mathrm{Nu}_{1}^{-}\right)$in a Wacker type process to generate a $\pi$-allyl palladium intermediate $\mathbf{A}$, which can then undergo a substitution reaction with another nucleophile $\left(\mathrm{Nu}_{2}{ }^{-}\right)$to afford either a 1,2- or a 1,4-product, and to release the $\operatorname{Pd}(0)$, which is oxidized into catalytically active $\operatorname{Pd}(\mathrm{II})$ for the next catalytic cycle (Scheme 1, eq. 1 ). The palladium(0) complex has also been shown to enable various difunctionalization reactions after it undergoes an oxidative addition to a high oxidation state compound and a subsequent Heck insertion of the 1,3-diene to form a $\pi$-allyl palladium species $\mathbf{B}$, which ultimately reacts with a nucleophile to generate a 1,2 - or 1,4-addition-like product (Scheme 1, eq. 2).
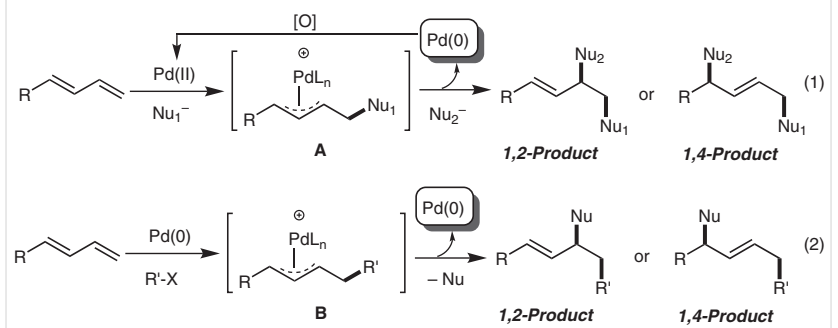

Scheme 1 Pd-catalyzed difunctionalization of 1,3-dienes

Considering that a variety of excellent reviews have summarized the metal-catalyzed enantioselective difunctionalization of the 1,2- or 1,4- positions of 1,3-dienes, ${ }^{4 e, 4 f, 5}$ this short review mainly focuses on highlighting $\operatorname{Pd}(0)$-catalyzed difunctionalization of 1,3-dienes. As shown in Scheme 2, the $\operatorname{Pd}(\mathrm{II})$ intermediate I, generated from an oxidative addition reaction of a $\operatorname{Pd}(0)$ complex to an R-X, undergoes a Heck insertion reaction to give an allylic palladium intermediate II, which will be able to undergo isomerization to form a $\pi$-allyl palladium intermediate III. The $\pi$ allyl palladium species III then participates in an allylic alkylation reaction with a stabilized carbon nucleophile by direct back-side attack at one of the allylic terminuses, principally giving rise to either a 1,2-product or a 1,4-product and releasing $\operatorname{Pd}(0)$ (Path A). Alternatively, a transmetalation at the palladium of intermediate III gives $\pi$-allyl palladium intermediate $\mathbf{I V}$, which then undergoes a reductive elimination to generate a 1,2-product or a 1,4-product and release $\operatorname{Pd}(0)$ (Path B).

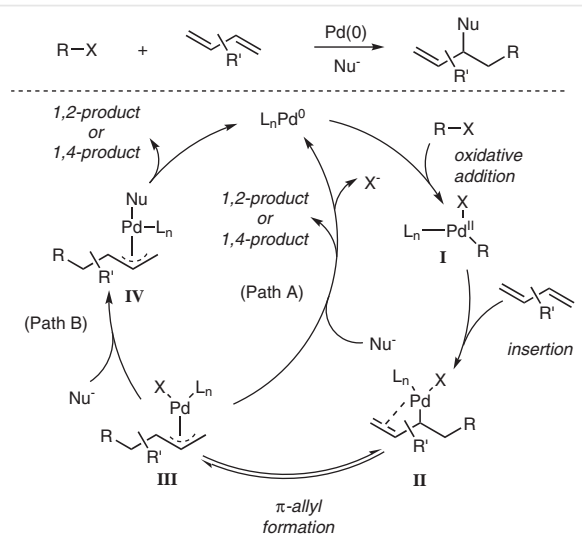

Scheme 2 Putative catalytic cycle for the $\operatorname{Pd}(0)$-catalyzed difunctionalization of 1,3-dienes

\section{Amination}

\subsection{Three-Component Arylation or Vinylation/Ami- nation}

The first example of $\operatorname{Pd}(0)$-catalyzed three-component difunctionalization of 1,3-dienes was reported by Heck's group in $1978 .{ }^{6}$ They initially planned to synthesize conjugated dienes from bromobenzene or 2-bromopropene with isoprene by palladium-catalyzed arylation; unexpectedly, regiospecific 1,4-difunctionalized allylic amines $\mathbf{1}$ and $\mathbf{2}$ were obtained when a large excess of secondary amine (piperidine or morpholine) was employed in the reaction (Scheme 3, eqs. 1 and 2). ${ }^{6}$ In contrast to acyclic dienes, 1,3cyclohexadiene provided both 1,2- and 1,4-products (Scheme 3, eqs. 3 and 4). 7.8

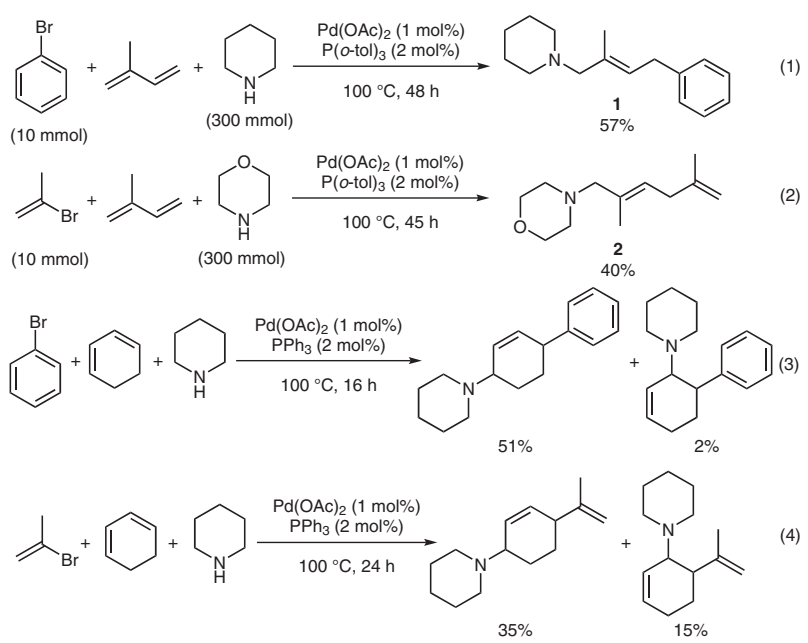

Scheme 3 Three-component arylation or vinylation/amination 
Moreover, Dieck and co-workers also found that a broad scope of amines such as ethyl amine, diethyl amine, $n$-butylamine, tert-butylamine and pyrrolidine could work as nucleophiles to participate in the arylation/amination and to yield 1,2- and 1,4-products (Scheme 4). ${ }^{9}$

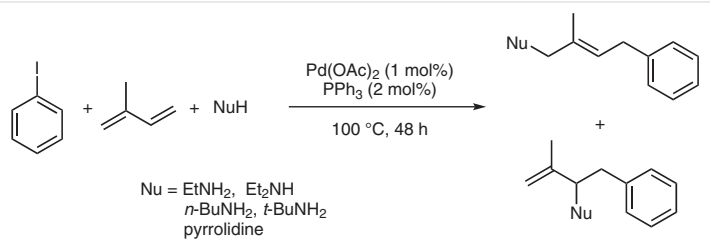

Scheme 4 Amine nucleophiles for the three-component arylamination

\subsection{Arylation/Intramolecular Amination}

At the same time, Dieck's group reported a cascade arylation and intramolecular amination reaction of $o$-iodoaniline with isoprene and 1,3-cyclohexadiene, to generate 2isopropenyl-2,3-dihydroindole 3 (72\%) and la,3,4,4a-tetrahydrocarbazole $4(70 \%)$, respectively (Scheme 5$).{ }^{9}$

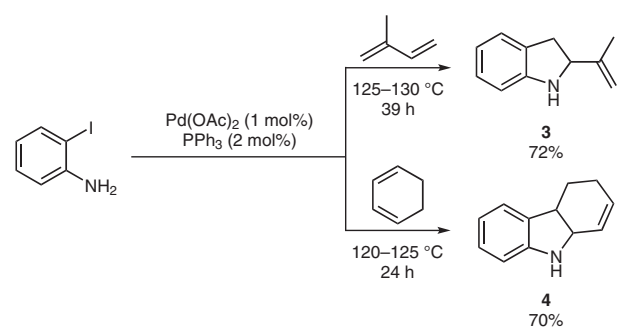

Scheme 5 Arylation/intramolecular amination cascade

Larock and co-workers then developed an even more efficient heteroannulation reaction of 1,3-dienes with 2-iodophenyltosyl amide, leading to dihydroindole $\mathbf{5}$ and tetrahydrocarbazole 6 in higher yields (Scheme 6). ${ }^{10}$ 2-Iodobenzylic tosyl amides also turned out to be excellent substrates to furnish six-membered nitrogeneous heterocycles $\mathbf{7}$.

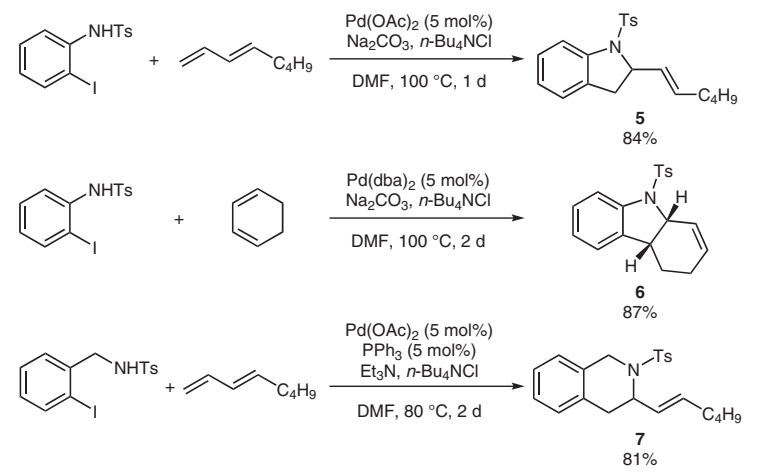

Scheme 6 Arylation/intramolecular amination cascade to generate dihydroindole, tetrahydrocarbazole and six-membered ring nitrogen heterocycles
Inspired by Dieck ${ }^{9}$ and Larock's ${ }^{10}$ pioneering work, Han and co-workers described the first $\mathrm{Pd}(0)$-catalyzed enantioselective heteroannulation of 1,3-dienes with 2-iodoanilines (Scheme 7) ${ }^{11}$ Chiral indolines 8 were obtained in up to $83 \%$ yield and with fairly good enantioselectivities of up to $87 \%$ ee. The employment of a BINOL-derived phosphoramidite ligand L1 bearing electron-withdrawing substituents is the key to delivering high enantioselectivity.

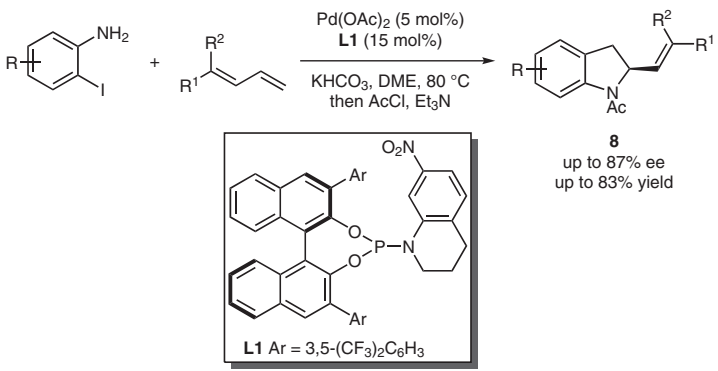

Scheme 7 Enantioselective cascade arylation/intramolecular amination reaction to access chiral indolines assisted by chiral BINOL-derived phosphoramidite ligand

In 1999, Helmchen reported an enantioselective tandem Heck/intramolecular allylic amination reaction using amino group tethered 1,3-dienes and aryltriflates as substrates (Scheme 8).$^{12}$ Chiral PHOX ligand $\mathbf{L 2}$ allowed the reaction to give chiral piperidine $\mathbf{1 0}$ with $80 \%$ ee. Compared to the aryliodides, aryltriflates $\mathbf{9}$ gave higher enantioselectivities, but required prolonged reaction time of 10 days.

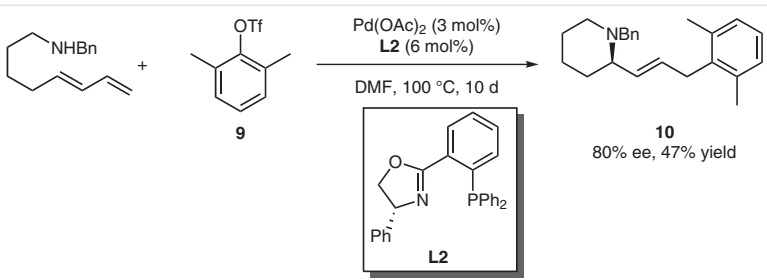

Scheme 8 Enantioselective arylation/intramolecular amination for the synthesis of chiral piperidine

\subsection{Intramolecular Arylation or Vinylation/Amina- tion}

In 1989, Grigg and co-workers found that dienamide group tethered phenyliodide $\mathbf{1 1}$ could undergo a $\mathrm{Pd}(0)$-catalyzed intramolecular 5-exo-trig cyclization on a proximate diene functionality to generate $\pi$-allyl-palladium species, which was subsequently captured by secondary amines, including morpholine, piperidine or 1,2,3,4-tetrahydroisoquinoline, giving 1,4-products 12 in $40-60 \%$ yield (Scheme 9). ${ }^{13}$

In 1993, Shibasaki's group reported a Pd/BINAP-catalyzed intramolecular asymmetric Heck reaction/allylic amination reaction (Scheme 10). ${ }^{14}$ Under the catalysis of a chi- 


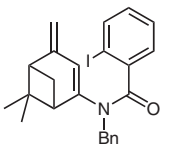

11
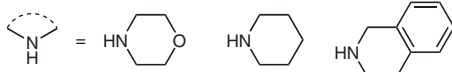

Scheme 9 Racemic intramolecular arylation/amination

ral complex formed in situ from $\mathrm{Pd}(\mathrm{OAc})_{2}$ and $(S)$-BINAP, prochiral alkenyl triflate $\mathbf{1 3}$ and benzylamine underwent a vinylamination to give a bicyclic product 14 with three continuous chiral centers in $76 \%$ yield and with $81 \%$ ee.

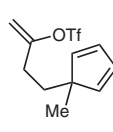

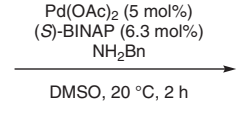

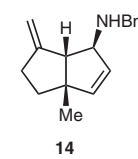

$81 \%$ ee, $76 \%$ yield

Scheme 10 Enantioselective intramolecular vinylation/amination
The Pd-catalyzed intramolecular arylamination has been applied in the total synthesis of a natural product by Overman and co-workers (Scheme 11). ${ }^{15}$ The catalytic asymmetric Heck cyclization/allylic amination reaction of (2Z)-2,4-hexadienamide tethered diketopiperazine precursor 15 in the presence of $\operatorname{Pd}_{2}(\mathrm{dba})_{3}$ and $(S)$-BINAP produced pentacyclic products 16 and 17 in 6:1 ratio and 28\% combined yield. Interestingly, when ligand $(R)$-BINAP was used, a 1:6 diastereomeric mixture of pentacyclic products $\mathbf{1 6}$ and $\mathbf{1 7}$ was obtained with similar efficiency. However, the use of tri-o-tolylphosphine as the ligand enabled (2E)-2,4hexadienamide 18 to give a 1:1 mixture of pentacyclic products 19 and 20, attributed to the anti-capture of the initially produced $\mathrm{n}^{3}$-allylpalladium intermediate. Removal of the SEM group from the product 19 provided optically pure (-)spirotryprostatin B. Notably, the other three stereoisomers could also be obtained by following a similar procedure.

\subsection{Aminomethylamination}

To expand the application of the aminal activation concept, ${ }^{16}$ Huang and co-workers recently described a highly enantioselective aminomethylamination reaction of 1,3 dienes with aminals enabled by a chiral palladium complex of BINOL-derived chiral diphosphinite L3 (Scheme 12). ${ }^{17}$ The reaction proceeded through a cascade reaction sequence of $\mathrm{C}-\mathrm{N}$ bond activation (P1), aminomethylation (P2), and asymmetric allylic amination reaction (P3), giving synthetically useful chiral 1,3-diamines 21 with high regioand enantioselectivity (Scheme 12).

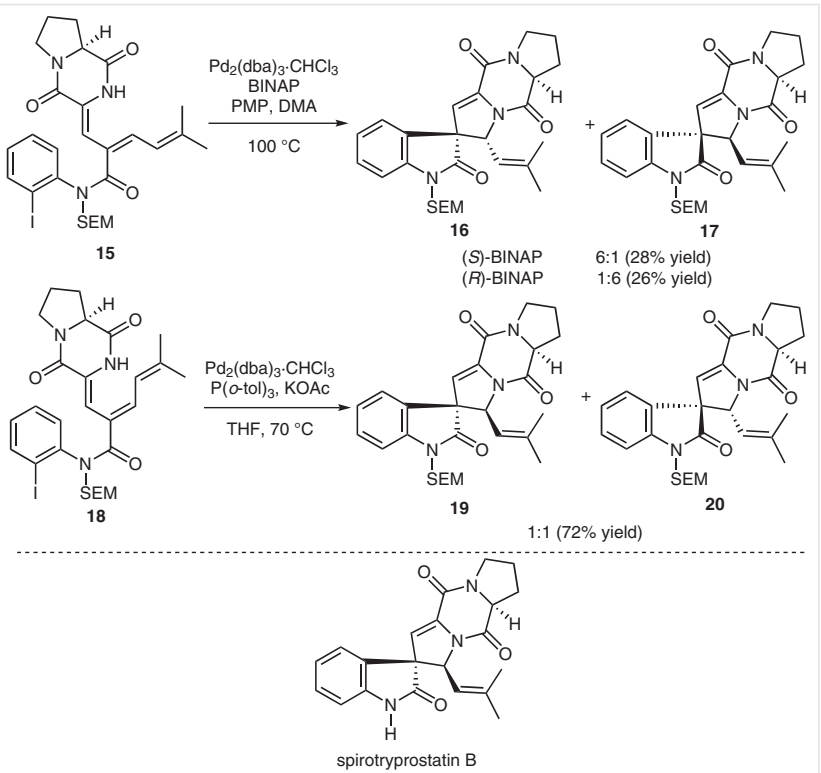

Scheme 11 Enantioselective intramolecular arylamination for the total synthesis (-)-spirotryprostatin B

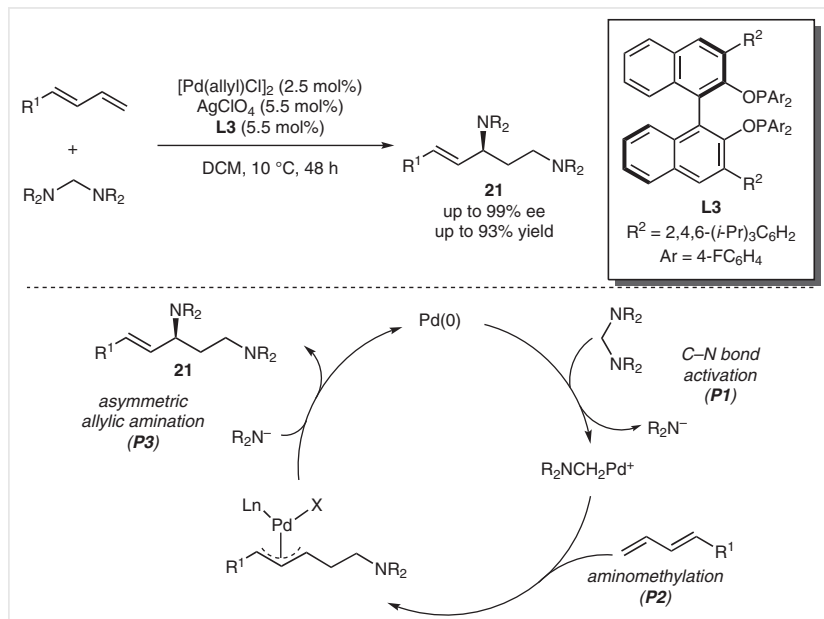

Scheme 12 Asymmetric intermolecular aminomethylamination of 1,3-dienes with an aminal

\subsection{Diamination}

Chiral vicinal diamine is a structural motif prevalently found in numerous biological compounds and appears to be a core structural element of chiral auxiliaries and ligands that have been widely applied in asymmetric synthesis. ${ }^{18}$ Metal-mediated or catalyzed diamination of olefins constitutes one of the most efficient approaches to access the skeleton. ${ }^{19}$

In 2007, Shi and co-workers reported that $\mathrm{Pd}\left(\mathrm{PPh}_{3}\right)_{4}$ could catalyze the diamination of a variety of conjugated dienes using di-tert-butyldiaziridinone $\mathbf{2 3}$ as nitrogen source to give the racemic imidazolidinones 24 in high 
yields (Scheme 13). ${ }^{20}$ In this reaction, the palladium complex first undergoes an oxidative addition to the $\mathrm{N}-\mathrm{N}$ bond of diaziridine to form a diamido Pd(II) species Int-1, which then reacts with the 1,3-diene to give a $\pi$-allyl Pd species Int-2 through a migratory insertion to the double bond and a subsequent reductive elimination to give diamination product $\mathbf{2 4}$ (Scheme 13). ${ }^{21,22}$ Among these elementary reactions, the migratory insertion of the double bond of 1,3-diene to the diamido $\mathrm{Pd}(\mathrm{II})$ intermediate Int-1 builds up the initial stereogenic center and the reductive elimination of $\pi$-allyl Pd species Int-2 leads to another one. Both events involve the palladium complex. Thus, the enantioselective version could in principal be accessed by exploiting chiral phosphine ligands. ${ }^{21}$ Shi and co-workers found that a palladium complex adorned with tetramethylpiperidine-derived and binol-based phosphoramidite ligand $\mathbf{L} \mathbf{4}$ enabled asymmetric diamination of 1,3-dienes to furnish the corresponding products $\mathbf{2 5}$ in good yields and with high levels of regio, diastereo-, and enantioselectivity (Scheme 14). Notably, the diamination takes place predominantly at the internal double bond of the 1,3-dienes. ${ }^{23}$

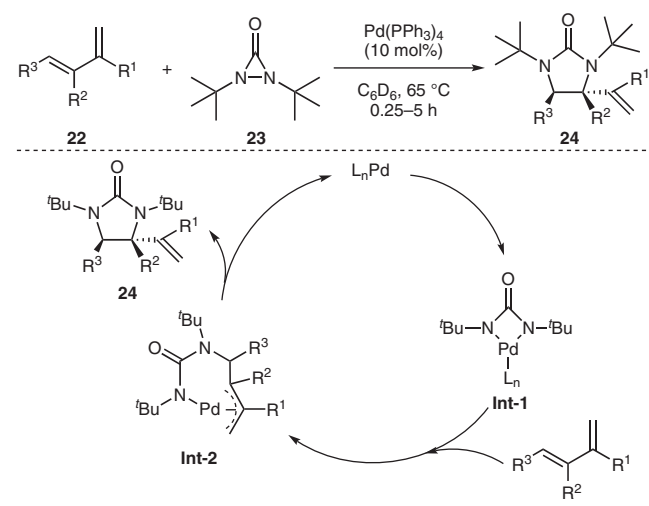

Scheme 13 Diamination of 1,3-dienes

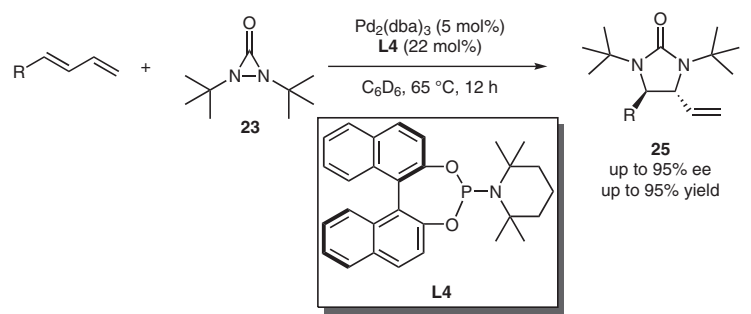

Scheme 14 Enantioselective diamination for the synthesis of chiral imidazolidinones assisted by a tetramethylpiperidine-derived phosphorus amidite ligand

Shi further found that N-heterocyclic carbine (NHC)$\operatorname{Pd}(0)$ complexes were also able to efficiently promote the diamination of 1,3-dienes with di-tert-butyldiaziridinone 23 (Scheme 15). ${ }^{24}$ Moreover, the chiral NHC-Pd(0) complex [Pd1]Cl was found to be more catalytically active than other tested ligands for the diamination. ${ }^{25}$

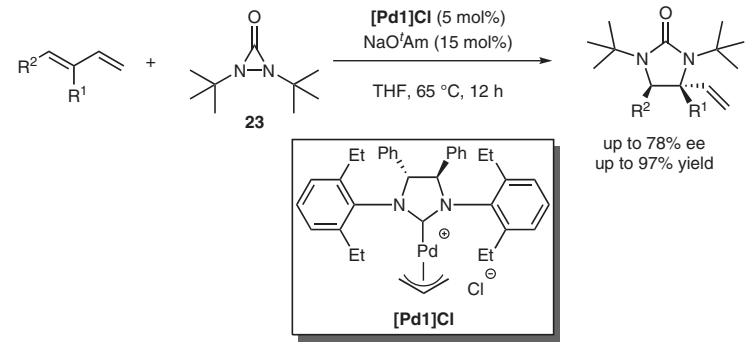

Scheme 15 NHC-Pd(0)-catalyzed asymmetric diamination

Di-tert-butylthiadiaziridine 1,1-dioxide $\mathbf{2 6}$ is also an active substrate to undergo Pd-catalyzed diamination of 1,3dienes. Optically active cyclic sulfamides $\mathbf{2 7}$ were manufactured in up to $98 \%$ yield and with up to $93 \%$ ee from the reaction of 1,3-dienes with $\mathbf{2 6}$ enabled by palladium catalyst generated from $\operatorname{Pd}_{2}(\mathrm{dba})_{3}$ and chiral phosphoramidite $\mathbf{L 5}$ (Scheme 16).

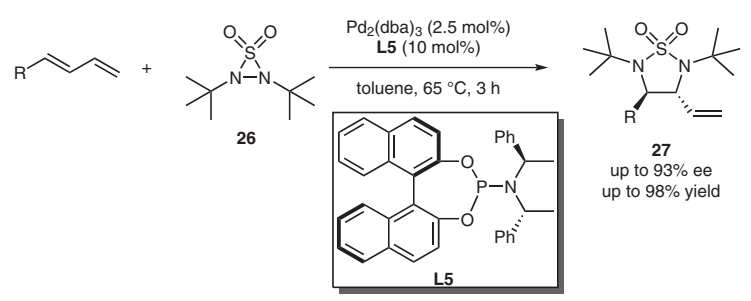

Scheme 16 Enantioselective diamination with di-tert-butylthiadiaziridine 1,1-dioxide

\subsection{Hydroamination}

Hydroamination refers to the direct addition of amines to unsaturated hydrocarbons, leading to amines. ${ }^{26} 1,3-$ Dienes and primary or secondary amines could undergo hydroamination smoothly in the presence of $\operatorname{Pd}(0)$ and appropriate ligands, in which $n^{3}-\mathrm{C}_{3} \mathrm{H}_{5} \mathrm{Pd}(\mathrm{II})$ complex are used widely as catalyst precursors. In the catalytic cycle (Scheme 17), an amine attacks the original $n^{3}-\mathrm{C}_{3} \mathrm{H}_{5}$ Pd salt to generate an ammonium salt 29 and $\operatorname{Pd}(0)$. Oxidative protonation with the ammonium salt then forms a transient Pd-H Int-3. Diene migratory insertion to the Pd-H intermediate initially leads to a Pd-б-allyl Int-4, which may isomerize into $\pi$-allyl intermediate Int-5. The subsequent attack by the amine generates a $\mathrm{Pd}^{0}$-allylic ammonium complex Int-6, which releases the product $\mathbf{2 8}$ and regenerates $\operatorname{Pd}(0)$.

In 2001, the Hartwig lab showed that aryamines could be added to cyclohexene in the presence of $\left[\mathrm{Pd}\left(\mathrm{n}^{3}-\mathrm{C}_{3} \mathrm{H}_{5}\right) \mathrm{Cl}\right]_{2}$ and Trost ligand $\mathbf{L} \mathbf{6}$ to give chiral 1,4-products $\mathbf{3 0}$ with up to 95\% ee (Scheme 18). ${ }^{27}$

Cationic $\mathrm{n}^{3}-\mathrm{C}_{3} \mathrm{H}_{5}$ palladium complexes [Pd2]OTf, prepared by the treatment of $\left[\mathrm{Pd}\left(\mathrm{n}^{3}-\mathrm{C}_{3} \mathrm{H}_{5}\right) \mathrm{Cl}\right]_{2}$ with 1,2-diaryl3,4-bis[(2,4,6-tri-tert-butylphenyl)phosphinidene]cy- 


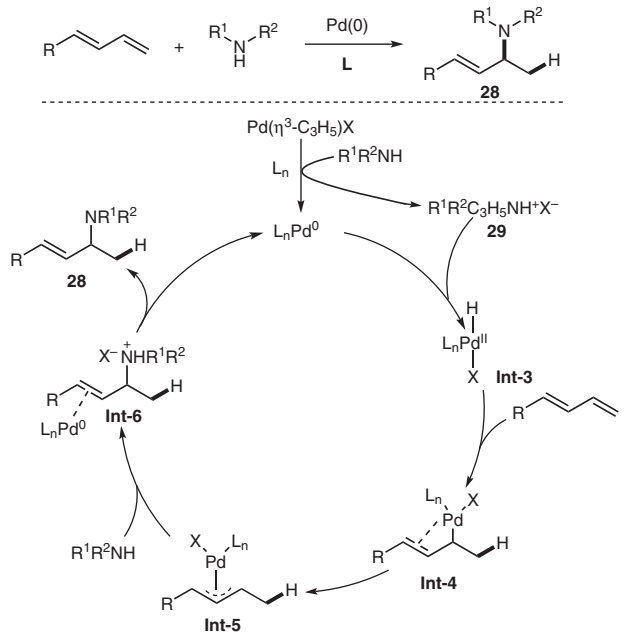

Scheme 17 Catalytic cycle for the hydroamination of 1,3-dienes

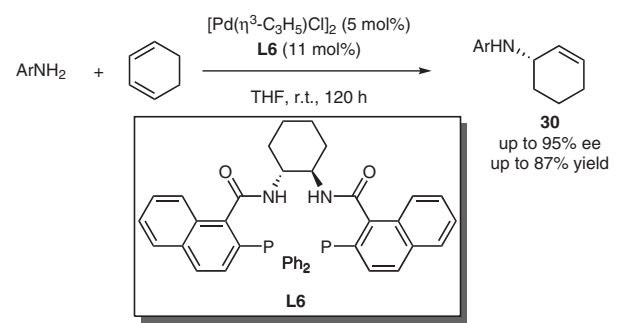

Scheme 18 Enantioselective hydroamination with symmetrical cyclic dienes

clobutenes and AgOTf in $\mathrm{CH}_{2} \mathrm{Cl}_{2}$, rendered the hydroamination of 1,3-cyclohexadiene with aniline at room temperature to give the corresponding 1,2-addition products $\mathbf{3 1}$ in high yields (Scheme 19). ${ }^{28}$ The use of diphosphinidenecyclobutene ligand with $\mathrm{sp}^{2}$-hybridized phosphorus atoms having strong-acceptor ability is critical for the catalytic activity.

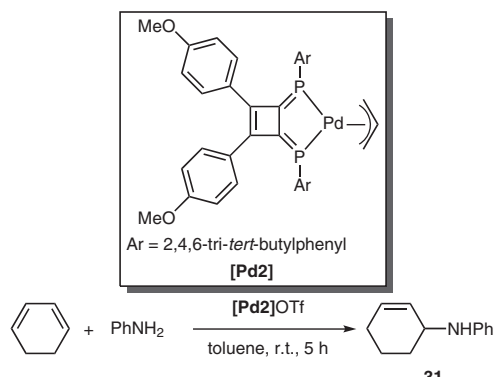

31

Scheme 19 [Pd2]OTf-catalyzed racemic hydroamination
Beller and co-workers reported a 1,4-hydroamination acyclic and cyclic dienes catalyzed by $\mathrm{Pd}(\operatorname{cod}) \mathrm{Cl}_{2}$ in combination with a bidentate phosphorus ligand DPEphos L7 (Scheme 20). ${ }^{29}$ The reaction proceeds in good yields and with high regioselectivity.

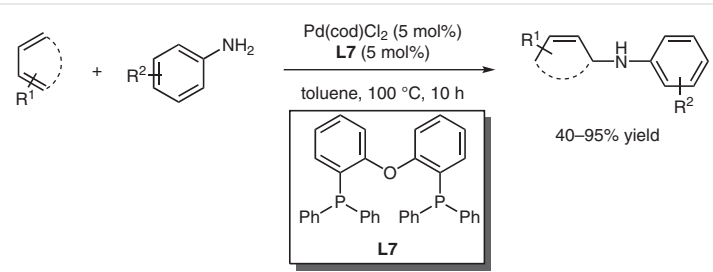

Scheme 20 Racemic 1,4-hydroamination of acyclic or cyclic dienes

In 2017, Malcolmson et al. established an enantioselective hydroamination of aliphatic amines with acyclic 1,3dienes, generating chiral allylic amines 32 in up to $94 \%$ ee (Scheme 21). ${ }^{30}$ Chiral PHOX ligand $\mathbf{L 8}$ involving an electrondeficient phosphine not only shows high reactivity in the transformation but also plays a special role in achieving high site and enantioselectivity for the 1,2-addition product. Notably, more electron-rich substituents on the diene have a dramatic effect on the formation of the 1,2-product.

$$
\text { }
$$

Scheme 21 Enantioselective hydroamination of aliphatic amines with acyclic 1,3-dienes

Very recently, the same group reported a highly enantio- and regioselective $\operatorname{Pd}(0)$-catalyzed hydroamination of 1,4-disubstituted acyclic internal 1,3-dienes, which are considered even more challenging substrates (Scheme $22) .{ }^{31} \mathrm{~A}$ variety of secondary aliphatic amines, indoline, and

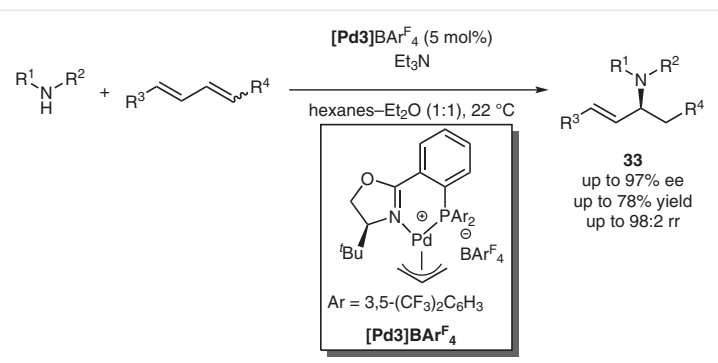

Scheme 22 Enantioselective hydroamination of 1,4-disubstituted acyclic internal 1,3-dienes 
primary anilines undergo the asymmetric 1,2-hydroamination reaction with a diverse spectrum of aryl/alkyldisubstituted dienes as well as sterically differentiated alkyl/alkyldisubstituted dienes, generating allylic amines $\mathbf{3 3}$ bearing various $\alpha$-alkyl substituents in up to $78 \%$ yield, with $>98: 2$ rr, and $97 \%$ ee.

\section{Boration}

The boration of 1,3-dienes has received a great deal of attention because it generates a diverse range of alkyl boronates, which are important intermediates and building blocks in synthetic organic chemistry. ${ }^{32} \mathrm{Fe},{ }^{33} \mathrm{Cu}^{34}$ or $\mathrm{Ir}^{35}$ catalyzed boration of 1,3-dienes has been investigated intensively by several groups; however, the $\operatorname{Pd}(0)$-catalyzed variants are relatively rare.

\subsection{Hydroboration}

The preparation of allylic boronates 36 from a 1,4-hydroboration of 1,3-dienes was initially reported by Suzuki's group in $1989 .{ }^{36}$ Under the catalysis of $\mathrm{Pd}\left(\mathrm{PPh}_{3}\right)_{4}$, the hydroboration of buta-1,3-diene, isoprene, myrcene or 2,3-dimethylbuta-1,3-diene with catecholborane (1,3,2-benzodioxaborole) 35 proceeds smoothly to provide 2 -[(Z)-2-alkyl2-butenyl]-1,3,2-benzodioxaboroles 36a-d with very high regio- and stereoselectivity, which are able to undergo carbonyl allylation with benzaldehyde to produce homoallylic alcohols 37 in high yields and diastereoselectivities (Scheme 23).

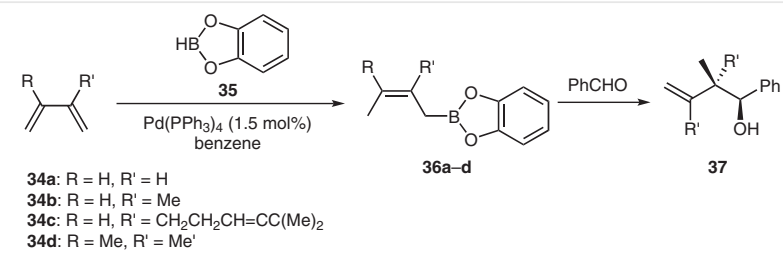

Scheme 23 Hydroborations of 1,3-dienes

\subsection{Arylboration}

Recently, Gong and co-workers reported a stereo- and regioselective multicomponent carbonyl allylation reaction of buta-1,3-dienes, aryldiazonium tetrafluoroborates, and aldehydes in the presence of octaphenyl-2,2'-bi(1,3,2-dioxaborolane) $\left[\mathrm{B}_{2}(\mathrm{Pin})_{2}\right]$, enabled by the combined catalysis of palladium acetate and chiral anion phase transfer, favoring the assembly of chiral Z-configured homoallylic alcohols 38 in high yields and with excellent levels of enantioselectivity (Scheme 24). ${ }^{37}$ The key chiral allylboronate intermediate Int-7, which then undergoes the asymmetric allylboryla- tion of aldehydes to give homoallylic alcohols, is initially generated from the arylborylation of a 1,3-diene with an aryldiazonium tetrafluoroborates and $\mathrm{B}_{2}(\mathrm{Pin})_{2}$ rendered by the palladium and chiral anion phase-transfer combined catalysis.

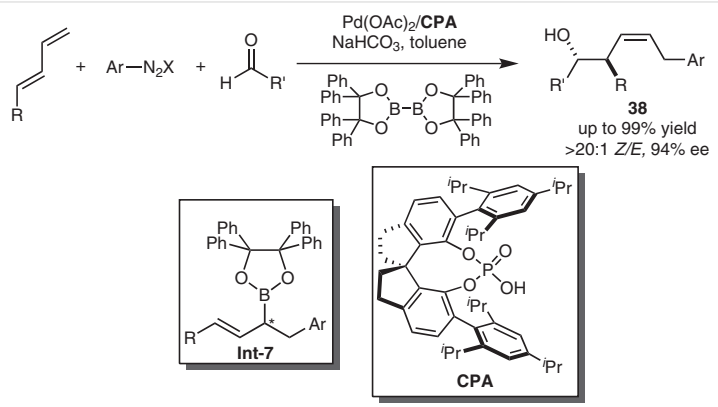

Scheme 24 Enantioselective alkynylboration with buta-1,3-dienes and alkynyl bromides

\subsection{Alkynylboration}

To extend the scope of the palladium and chiral anion phase-transfer combined catalysis for the difunctionalization of 1,3-dienes, Gong and co-workers established a multicomponent carbonyl allylation reaction of buta-1,3dienes, alkynyl bromides, and aldehydes with octaphenyl2,2'-bi(1,3,2-dioxaborolane) (Scheme 25). ${ }^{38}$ The alkynyl palladium phosphate Int-8 generated in situ from the metathesis reaction of a chiral silver phosphate and the alkynyl palladium bromide turns out to be a key intermediate that controls the stereoselectivity of chiral allylboronate intermediate Int-9.

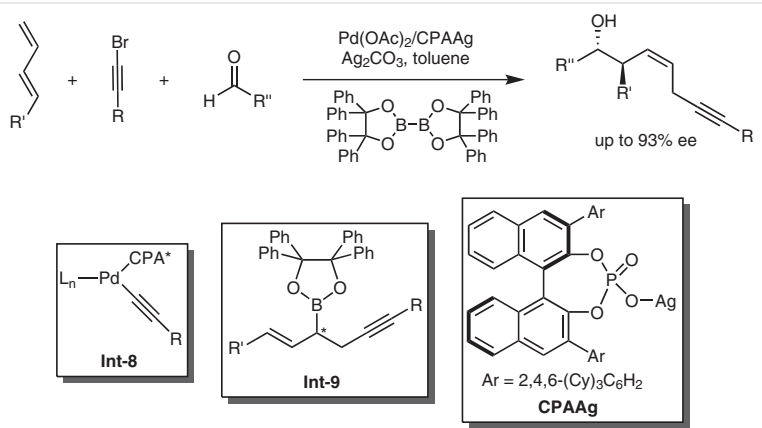

Scheme 25 Enantioselective alkynylboration with buta-1,3-dienes and alkynyl bromides

\section{Carbonation}

In addition to heteroatom nucleophiles, stabilized carbanions such as ${ }^{-} \mathrm{CH}(\mathrm{CN})_{2},{ }^{-} \mathrm{CH}(\mathrm{CN}) \mathrm{CO}_{2} \mathrm{R}$ or ${ }^{-} \mathrm{CH}\left(\mathrm{CO}_{2} \mathrm{R}\right)_{2}$ have been widely employed in the Pd-catalyzed carbonation of 1,3-dienes. 


\subsection{Vinyl or Arylation/Alkylation}

In 1983, Dieck and co-workers reported the first vinylalkylation reaction of 1,3-dienes with dimethyl sodiomalonate and 1-bromo-2-methylpropene catalyzed by palladium complex formed from $\mathrm{Pd}(\mathrm{OAc})_{2}$ and $\mathrm{PPh}_{3}$, to give the corresponding 1,4-selective product $\mathbf{3 9}$, albeit in moderate yield (Scheme 26). ${ }^{9}$

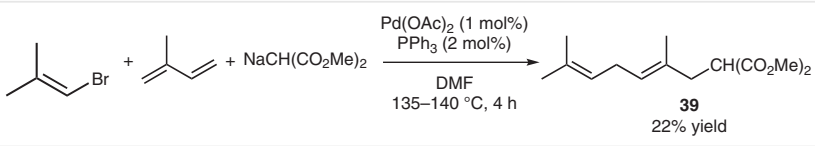

Scheme 26 Vinylalkylation with 1-bromo-2-methylpropene

In 1987, Takahashi and co-workers described a Pd-catalyzed three-component arylalkylation of buta-1,3-diene with aryliodide and malononitrile or methyl cyanoacetate, allowing for the generation of the corresponding 1,4-products $\mathbf{4 0}$ and $\mathbf{4 1}$ with iodobenzene and buta-1,3-diene in moderate yields (Scheme 27). ${ }^{39}$

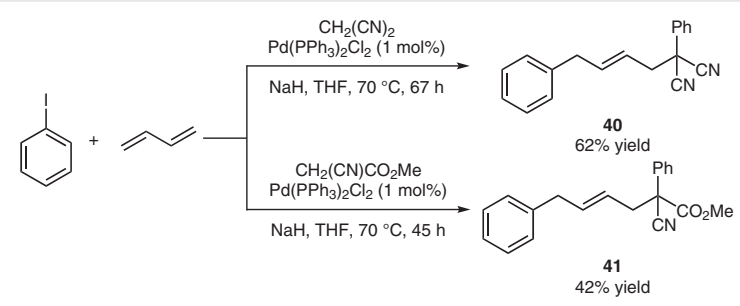

Scheme 27 Arylalkylation with iodobenzene

\subsection{Intramolecular Arylation or Vinylation/Alkyla- tion}

Grigg and co-workers demonstrated that the sodiomalononitrile could attack the $\pi$-allyl-palladium species, which is catalytically generated from an intramolecular 5exo-trig cyclization on a proximate diene mediated with Pd complex, to afford the corresponding regiospecific 1,4product 42 in $60 \%$ yield (Scheme 28 ). ${ }^{13}$

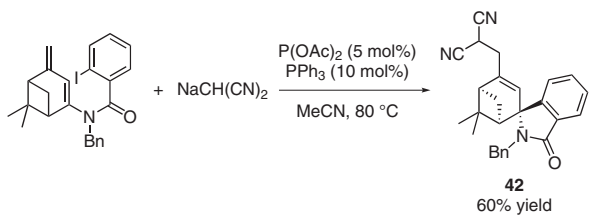

Scheme 28 Intramolecular arylalkylation

By using BINAP as a chiral ligand, Shibasaki established an intramolecular asymmetric Heck insertion and allylic alkylation cascade reaction (Scheme 29). ${ }^{40}$ An optically active functionalized bicyclo[3.3.0]octane $\mathbf{4 3}$ could be feasibly ac- cessed by this reaction and was used as a chiral building block for the first catalytic asymmetric total synthesis of $(-)-\Delta^{9(12)}$-capnellene. Interestingly, the addition of sodium bromide improved the enantioselectivity without erosion of the chemical yield in all cases by preventing counteranion exchange between the triflate anion and the enolate anion by coordination with sodium enolate.

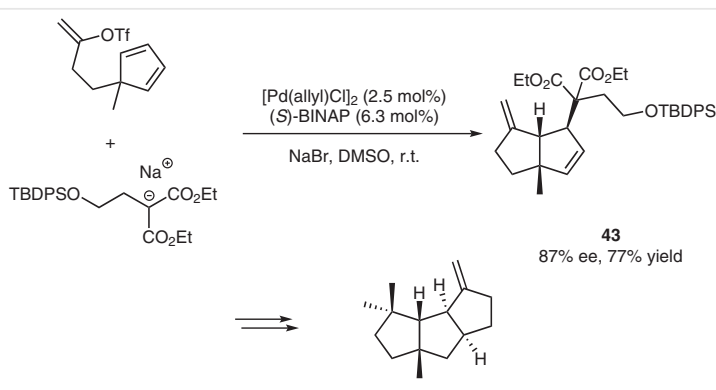

$(-)$-capnellene

Scheme 29 Enantioselective intramolecular arylalkylation for the total synthesis of $(-)-\Delta^{9(12)}$-capnellene

\subsection{Arylation/Intramolecular Alkylation}

In parallel with the development of heteroannulation of 1,3-dienes, ${ }^{10}$ Larock and co-workers also accomplished an intramolecular carboannulation of 1,3-dienes with aryl iodides to give indanes $\mathbf{4 4}$ and tetralins $\mathbf{4 5}$ in high yields (Scheme 30). ${ }^{41}$ In addition to malonate-type nucleophiles, other carbon nucleophiles $\alpha$ to an ester, a ketone or a nitrone functionality were also tolerated, as exemplified by 46-48, to afford the corresponding products in good yields. Nevertheless, a palladium-catalyzed annulation of 1,4dienes using ortho-functionally substituted aryl halides was also developed by the same group. ${ }^{42}$

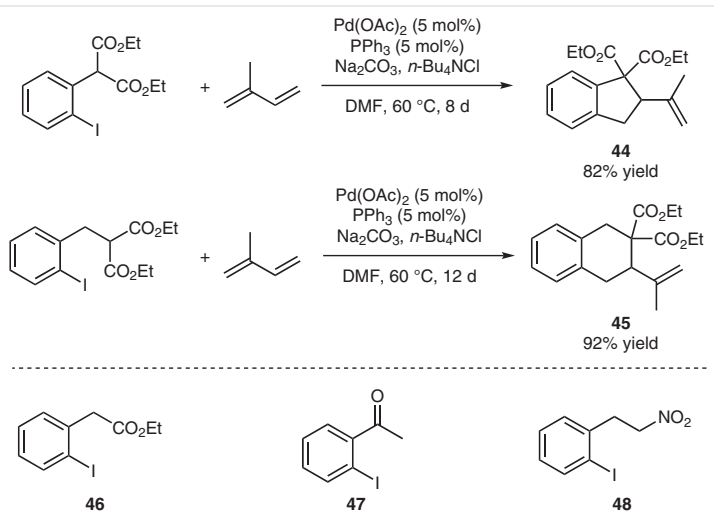

Scheme 30 Arylation/intramolecular alkylation for the synthesis of indane and tetralin

The enantioselective carboannulation of 1,3-dienes and aryl iodides was very recently established by Gong and coworkers. The use of chiral palladium complex of BINOL- 
based phosphoramidite ligand $\mathbf{L 9}$ allowed the reaction to provide optically active indanes $\mathbf{4 9}$ in high yields and with excellent enantiomeric excesses (Scheme 31 ). ${ }^{43}$

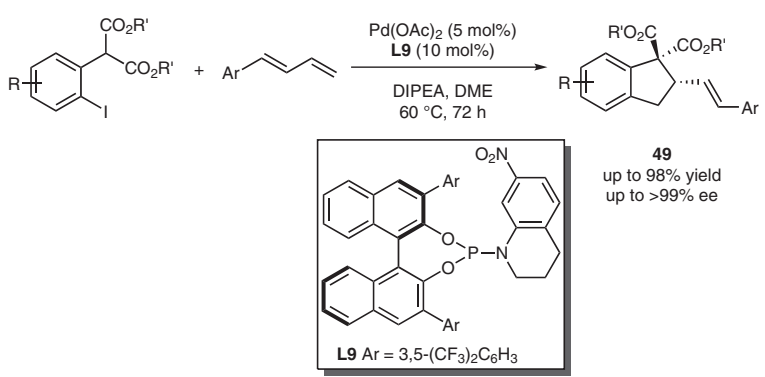

Scheme 31 Enantioselective carboannulation of 1,3-dienes and aryl iodides by using a BINOL-based phosphoramidite ligand

\subsection{Three-Component Arylation, Vinylation or Al- kylation}

In 2011, Sigman and co-workers reported a three-component coupling reaction of vinyl triflates and boronic acids with terminal 1,3-dienes catalyzed by palladium to give 1,2-vinylarylation product 50 (Scheme 32 ). ${ }^{44}$ The Pd- $\pi$-allyl intermediate int-10 tends to undergoing transmetalation with a boronic acid derivative rather than $\beta$-hydride elimination, after reductive elimination to give the products $\mathbf{5 0}$.

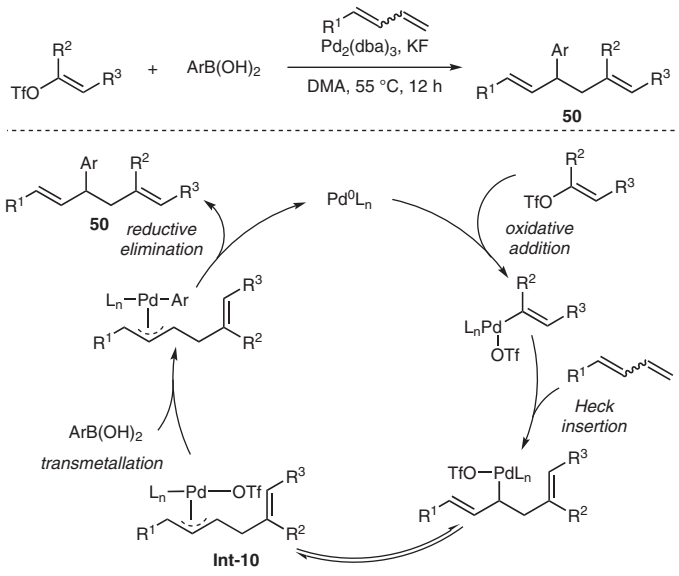

Scheme 32 Three-component vinylarylation

In 2015, the same group reported a three-component coupling of isoprene, an alkenyl triflate, and styrenylboronic acid to produce skipped polyenes from simple chemical feedstocks (Scheme 33). ${ }^{45,46}$ However, complex isomeric product mixtures 51-53 were always obtained because of the difficult-to-control migratory insertion of isoprene into a Pd-alkenyl bond, while a good site selectivity of 1,4-addi-

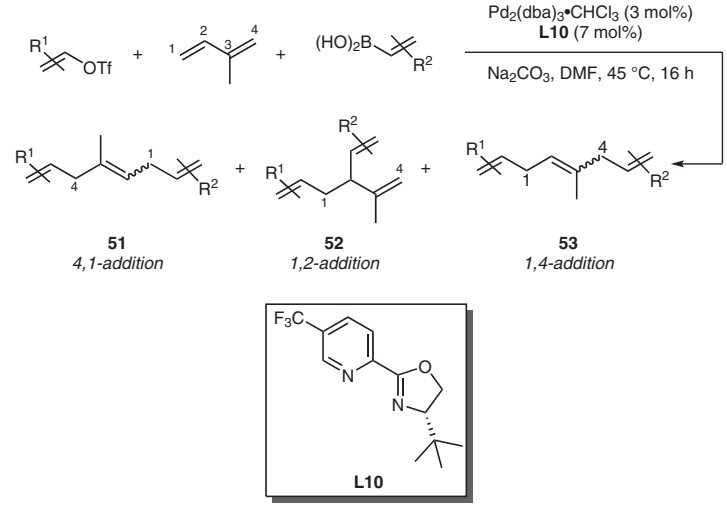

Scheme 33 Three-component coupling of isoprene, an alkenyl triflate, and styrenylboronic acid for the synthesis of skipped polyenes

tion (for the generation of 53) can be achieved by using easily accessible pyrox ligand $\mathbf{L 1 0}$.

Subsequently, Sigman and co-workers reported an intermolecular 1,2-diarylation reaction of 1,3-dienes with aryldiazonium salts and aryl boronic acids, allowing the installation of two different aryl groups (Scheme 34$).{ }^{47}$ In the presence of a chiral bicyclo[2.2.2]octadiene ligand L11, a good enantiomeric excess was obtained, albeit in rather low yield.

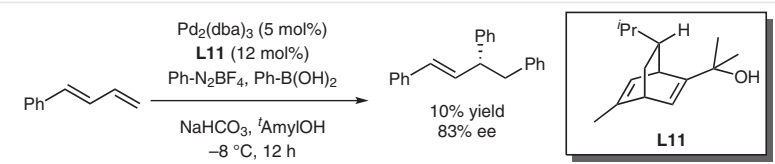

Scheme 34 Asymmetric 1,2-diarylation

In 2015, Gong and co-workers successfully established a highly enantioselective three-component coupling of 1,3dienes with aryl iodines and stabilized carbon nucleophiles (sodium dialkyl malonates) (Scheme 35). ${ }^{48} \mathrm{~A} \mathrm{H}_{8}$-BINOLbased phosphoramidite $\mathbf{L 1 2}$ turned out to be the most effective chiral ligand, which not only provides high catalytic activity, but is also able to efficiently control the regio- and stereoselectivity.

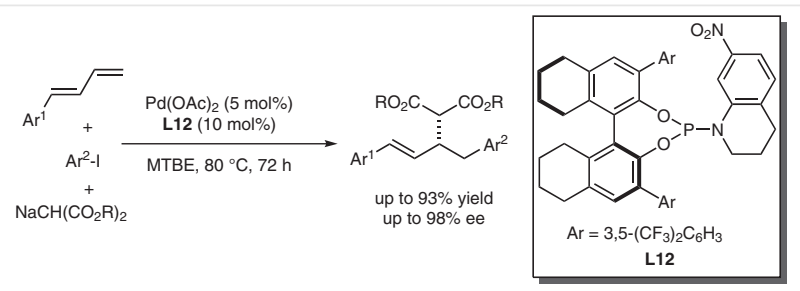

Scheme 35 Enantioselective three-component coupling of 1,3-dienes with aryl iodines and sodium dialkyl malonates 


\subsection{Others}

Yoshida and Ihara reported a cascade insertion-ring expansion reaction of 1,3-dienylcyclobutanols with aryl iodides to generate (Z)-2-(3-aryl-1-propenyl)cyclopentanones 54 in a stereospecific manner (Scheme 36). ${ }^{49}$ In the reaction, an arylpalladium complex formed from aryl iodide with palladium( 0$)$ undergoes a Heck insertion reaction with 1,3-dienyl moiety to give an allylic palladium intermediate Int-11. The Int-11 reacts with a base to form a zwitterionic $\pi$-allylpalladium intermediate Int-12, which subsequently undergoes a ring rearrangement to furnish a ringexpanded product 54 and regenerate the palladium( 0$)$ catalyst.

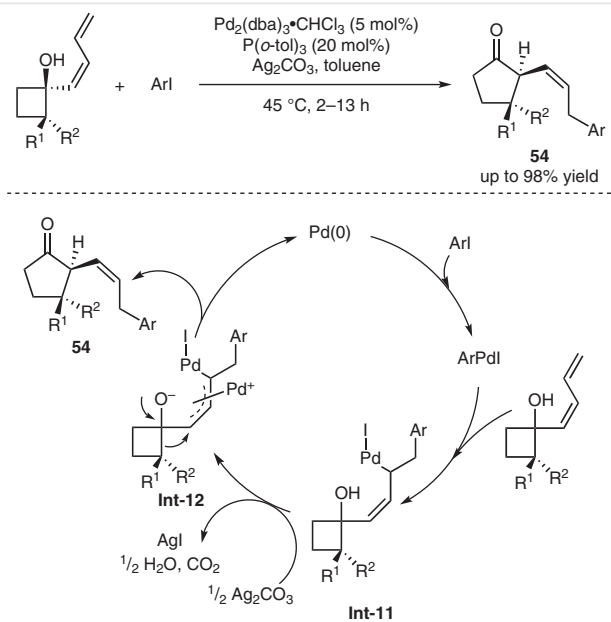

Scheme 36 Cascade insertion-ring expansion reaction of 1,3-dienylcyclobutanols with aryl iodides for the synthesis of (Z)-2-(3-aryl-1-propenyl)cyclopentanones

Recently, Luan and co-workers described a Pd-catalyzed dearomatization reaction of phenol-derived biaryls with 1,3-dienes to generate spirocyclic compounds $\mathbf{5 5}$ in good yields and with excellent chemo- and regioselectivity (Scheme 37). ${ }^{50}$ The reaction proceeds through a reaction sequence of oxidative addition (P4, Scheme 38) to the C-I bond, regioselective olefin insertion (P5), and allylative dearomatization (P6).

Preliminary studies on the enantioselective version revealed that chiral phosphoramidite ligand ent-L5 could allow the reaction to yield spirocyclic compounds with good enantioselectivities (Scheme 38). ${ }^{50}$

In a continuation of the asymmetric hydroamination of 1,3-dienes, ${ }^{30,31}$ Malcolmson and co-workers recently described a highly efficient and enantioselective intermolecular addition of activated C-pronucleophiles to acyclic 1,3dienes enabled by Pd catalysts $\left([\mathbf{P d 4}] \mathrm{BF}_{4}\right.$ or $\left.[\mathbf{P d 5}] \mathrm{BF}_{4}\right)$ bear-

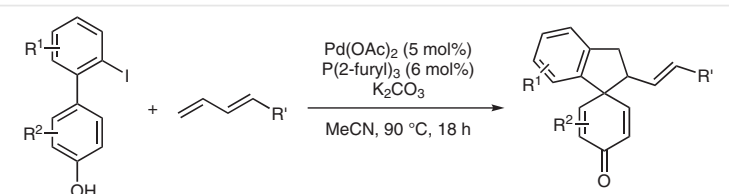

55

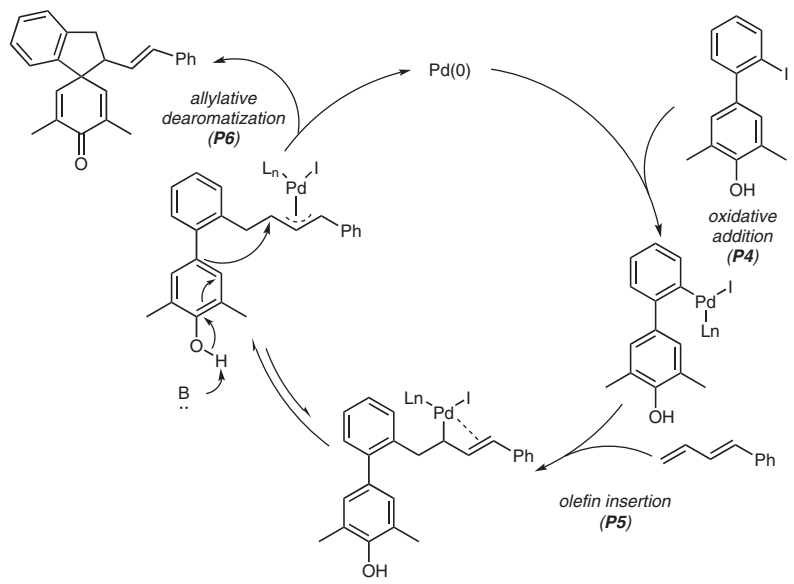

Scheme 37 Dearomatization reaction of phenol-derived biaryls with 1,3-dienes for the synthesis of spirocyclic compounds

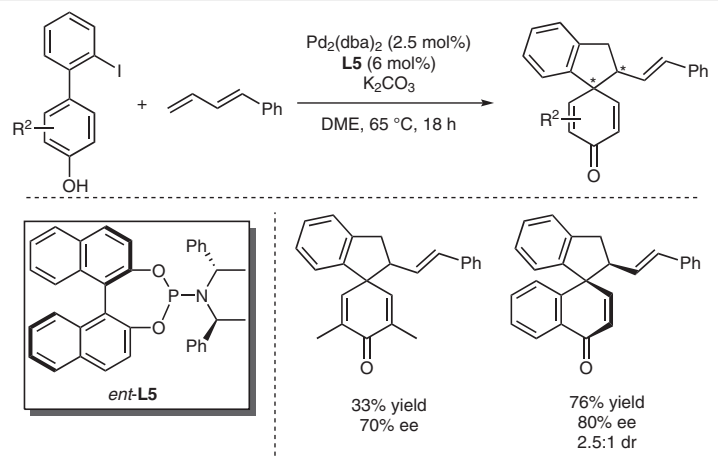

Scheme 38 Preliminary studies on asymmetric reaction

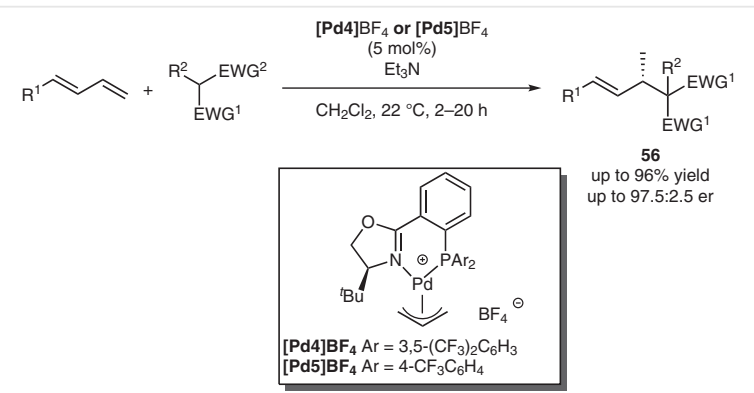

Scheme 39 Enantioselective hydroalkylation

ing electronically deficient phosphines (Scheme 39). ${ }^{51}$ The 1,2-difunctionalized products $\mathbf{5 6}$ could be obtained in up to $96 \%$ yield and $95 \%$ ee. 


\section{Hydrogenation}

Sigman and co-workers recently reported the only example to date of regio- and stereoselective 1,2-vinylhydrogenation of terminal 1,3-dienes with enol triflates/nonaflates in the presence of sodium formate (Scheme 40$){ }^{52}$ Trapping of the $\pi$-allyl intermediate generated from the initial migratory insertion of the diene with a hydride source allows access to structurally complex and synthetically challenging stereodefined $(E)$ - and $(Z)$-tri- and tetrasubstituted alkene building blocks 57.

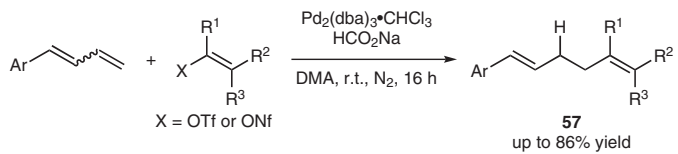

Scheme 40 1,2-Vinylhydrogenation of (E)- and (Z)-tri- and tetrasubstituted alkene

\section{Oxygenation}

Larock and co-workers created a Pd-catalyzed oxyannulation of 1,3-dienes with 0 -iodophenol substrates to give dihydrobenzofuran products (Scheme 41). ${ }^{10}$ Cyclohexa-1,3diene, 1-butyl-1,3-butadiene and 2-methylbuta-1,3-diene underwent facile intramolecular oxyannulation to deliver the corresponding dihydrobenzofurans 58-60 in moderate yields (Scheme 41, eqs. 1-3). The reaction of 0 -iodophenol and isoprene affords compound $\mathbf{6 0}$ in reasonable yield (Scheme 41, eq. 3), although a minor amount of a regioisomer is observed. Phenols bearing electron-withdrawing

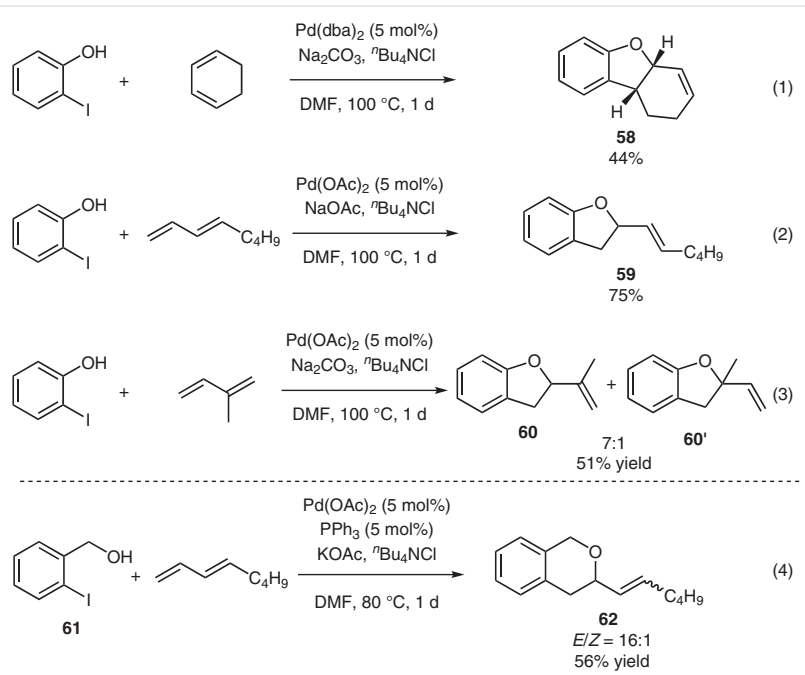

Scheme 41 Arylation/intramolecular oxygenation to generate dihydrobenzofuran and isochroman derivatives groups such as aldehydes and ketones generally give higher yields. Particularly, $\boldsymbol{o}$-iodobenzyl alcohol can be employed to form isochroman derivative $\mathbf{6 2}$ (Scheme 41, eq. 4).

Recently, Han and co-workers realized an asymmetric version of the Pd-catalyzed difunctionalization between 0 iodobenzyl alcohol and arylbutadienes (Scheme 42). ${ }^{11}$ Under similar conditions in the synthesis of chiral indolines, ${ }^{11}$ chiral isochromans 63a-d could be obtained with high enantioselectivities and moderate yields.

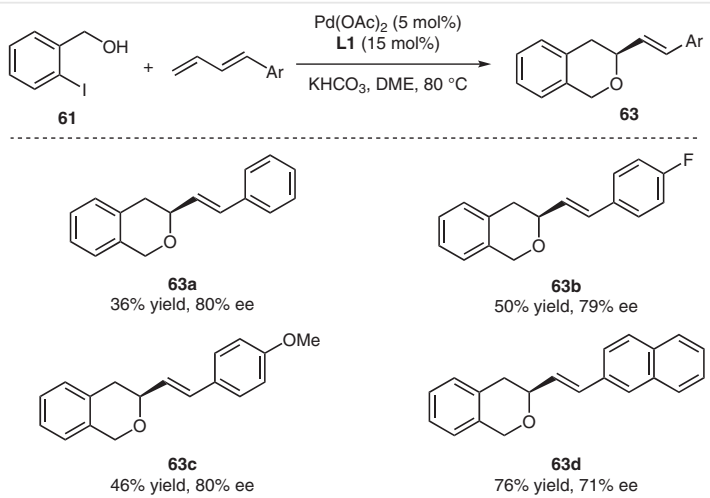

Scheme 42 Enantioselective arylation/intramolecular oxygenation to generate chiral isochromans

In 2005, Yeh and co-workers reported a palladium-catalyzed difunctionalization of 7-hydroxy-1,3-dienes with aryl bromides (Scheme 43). ${ }^{53}$ The reaction proceeded through different paths depending on the structure of the substrates. With cyclic 7-hydroxy-1,3-dienes 64, the insertion of a $\mathrm{C}-\mathrm{C}$ double bond into the $\mathrm{Pd}-\mathrm{O}$ bond of the initially formed $\mathrm{Pd}(\mathrm{Ar})(\mathrm{OR})$-olefin complex Int-13 is predominant and results in the formation of 1,4-alkoxyarylation product 66. In contrast, the reaction of acyclic 7-hydroxy-1,3-dienes

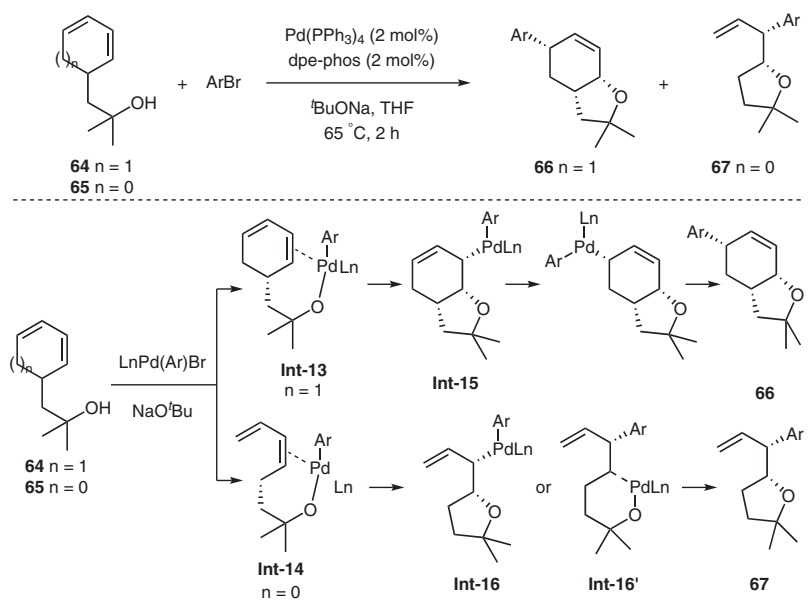

Scheme 43 Difunctionalization of 7-hydroxy-1,3-dienes with aryl bromides 
65 proceeded through the insertion of the double bond into either the $\mathrm{Pd}-\mathrm{C}$ or the $\mathrm{Pd}-\mathrm{O}$ bond of the $\mathrm{Pd}(\mathrm{Ar})-(\mathrm{OR})$-olefin intermediate Int-14 to afford 1,2-oxyarylation products 67 after reductive elimination. The difference in the formation of alkoxyarylation products (1,4- vs. 1,2-alkoxyarylation) between cyclic and acyclic substrates actually arises because the $n^{1}-n^{3}-n{ }^{1}$ allylic isomerization may be faster in the cyclic intermediate Int-15 than the acyclic intermediate Int-16 or Int-16' for steric reasons.

To synthesize capnellenol, a catalytic asymmetric cascade Heck reaction and allylic esterification was accomplished by Shibasaki. ${ }^{14,54}$ Various ligands and solvents were screened to reveal that the chiral palladium complex of $(S)$ BINAP delivered the best results in dimethyl sulfoxide (DMSO) (Scheme 44).

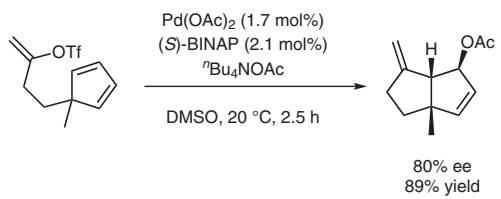

Scheme 44 Enantioselective intramolecular vinyloxygenation

\section{Silylation}

Optically active allylsilanes are useful reagents in stereoselective organic synthesis, because they are able to participate in asymmetric carbonyl or imine allylations with highly efficient chirality transfer. ${ }^{55}$ Increasing attention has been directed toward their asymmetric catalytic synthesis. Among the methods to access chiral allylsilanes, the palladium-catalyzed asymmetric hydrosilylation of 1,3-dienes has unique advantages, for example, using readily accessible starting materials. ${ }^{5}$ However, no breakthrough had been achieved in this field until recently. ${ }^{56}$ The chiral monodentate phosphine $\mathbf{L 1 3}$ with a binaphthyl moiety was identified as the most efficient ligand for the asymmetric hydrosilylation of cyclic 1,3-dienes whereas the planar chiral ferrocenylmonophosphine L14 with two ferrocenyl moieties turned out to be an efficient ligand for the reaction involving linear 1,3-dienes (Scheme 45). ${ }^{5}$

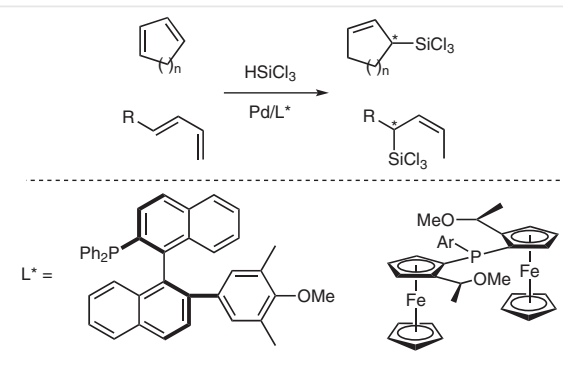

113

L14

Scheme 45 Asymmetric hydrosilylation of 1,3-dienes

\section{Conclusion and Outlook}

In the past forty years, the palladium(0)-catalyzed difunctionalization reactions of 1,3-dienes have made significant progress, culminating in a diverse range of transformations that provide efficient way to assemble densely functionalized molecules from readily available substances. Abundant availability of chiral ligands for the palladium( 0 ) catalysis has enabled switching the racemic reaction to an enantioselective version. Nevertheless, the stereochemical control remains a formidable challenge in the difunctionalization of 1,3-dienes, as indicated by the fact that many reactions are still not enantioselective. In addition, 1,3-diene components in these known processes are limited to aryl substituted or terminal dienes. Either alkyl substituted or internal acyclic dienes have rarely been reaction components in the asymmetric difunctionalization. Moreover, efficient control of regioselectivity is another big deal in such transformations. Therefore, new concepts, proper chiral ligands designed for Pd catalysis, and the development of new transformations for building up structural complexity will be future focuses in the difunctionalization of 1,3dienes.

\section{Funding Information}

We are grateful for financial support from NSFC (21672197, 21672049).

\section{References}

(1) (a) Morrow, N. L. Environ. Health Perspect. 1990, 86, 7. (b) White, W. C. Chem.-Biol. Interact. 2007, 166, 10.

(2) (a) De Paolis, M.; Chataigner, I.; Maddaluno, J. Top. Curr. Chem. 2012, 327, 87. (b) Olivares, A. M.; Weix, D. J. J. Am. Chem. Soc. 2018, 140, 2446. (c) Nguyen, V. T.; Dang, H. T.; Pham, H. H.; Nguyen, V. D.; Flores-Hansen, C.; Arman, H. D.; Larionov, O. V. J. Am. Chem. Soc. 2018, 140, 8434. (d) Hu, T.-J.; Li, M.-Y.; Zhao, Q.; Feng, C.-G.; Lin, G.-Q. Angew. Chem. Int. Ed. 2018, 57, 5871. (e) Fiorito, D.; Folliet, S.; Liu, Y.; Mazet, C. ACS Catal. 2018, 8, 1392. (f) Al-Jawaheri, Y.; Turner, M.; Kimber, M. C. Synthesis 2018, 50, 2329. (g) Matsumoto, K.; Mizushina, N.; Yoshida, M.; Shindo, M. Synlett 2017, 28, 2340. (h) Schmidt, B.; Audoersch, S.; Kunz, O. Synthesis 2016, 48, 4509.

(3) (a) Eschenbrenner-Lux, V.; Kumar, K.; Waldmann, H. Angew. Chem. Int. Ed. 2014, 53, 11146. (b) Sherburn, M.; Mackay, E. Synthesis 2014, 47, 1.

(4) (a) Sigman, M. S.; Werner, E. W. Acc. Chem. Res. 2012, 45, 874. (b) Jensen, K. H.; Sigman, M. S. Org. Biomol. Chem. 2008, 6, 4083. (c) McDonald, R. I.; Liu, G.; Stahl, S. S. Chem. Rev. 2011, 111, 2981. (d) Schultz, D. M.; Wolfe, J. P. Synthesis 2012, 44, 351. (e) Xiong, Y.; Sun, Y.; Zhang, G. Tetrahedron Lett. 2018, 59, 347. (f) Wu, Z.; Zhang, W. Chin. J. Org. Chem. 2017, 37, 2250.

(5) Han, J. W.; Hayashi, T. Tetrahedron: Asymmetry 2010, 21, 2193.

(6) Patel, B. A.; Dickerson, J. E.; Heck, R. F. J. Org. Chem. 1978, 43, 5018.

(7) Patel, B. A.; Kao, L. C.; Cortese, N. A.; Minkiewicz, J. V.; Heck, R. F. J. Org. Chem. 1979, 44, 918. 
(8) (a) Heck, R. F. Acc. Chem. Res. 1979, 12, 146. (b) Stakem, F. G.; Heck, R. F. J. Org. Chem. 1980, 45, 3584.

(9) Oconnor, J. M.; Stallman, B. J.; Clark, W. G.; Shu, A. Y. L.; Spada, R. E.; Stevenson, T. M.; Dieck, H. A. J. Org. Chem. 1983, 48, 807.

(10) Larock, R. C.; Berriospena, N.; Narayanan, K. J. Org. Chem. 1990, $55,3447$.

(11) Chen, S.-S.; Meng, J.; Li, Y.-H.; Han, Z.-Y. J. Org. Chem. 2016, 81, 9402.

(12) Flubacher, D.; Helmchen, G. Tetrahedron Lett. 1999, 40, 3867.

(13) Grigg, R.; Sridharan, V.; Sukirthalingam, S.; Worakun, T. Tetrahedron Lett. 1989, 30, 1139.

(14) Kagechika, K.; Ohshima, T.; Shibasaki, M. Tetrahedron 1993, 49, 1773.

(15) (a) Overman, L. E.; Rosen, M. D. Angew. Chem. Int. Ed. 2000, 39, 4596. (b) Overman, L. E.; Rosen, M. D. Tetrahedron 2010, 66, 6514.

(16) (a) Qin, G.; Li, L.; Li, J.; Huang, H. J. Am. Chem. Soc. 2015, 137, 12490. (b) Zhang, G.; Gao, B.; Huang, H. Angew. Chem. Int. Ed. 2015, 54, 7657. (c) Xie, Y.; Hu, J.; Xie, P.; Qian, B.; Huang, H. J. Am. Chem. Soc. 2013, 135, 18327. (d) Xie, Y.; Hu, J.; Wang, Y.; Xia, C.; Huang, H. J. Am. Chem. Soc. 2012, 134, 20613.

(17) Liu, Y.; Xie, Y.; Wang, H.; Huang, H. J. Am. Chem. Soc. 2016, 138, 4314.

(18) Lucet, D.; Le Gall, T.; Mioskowski, C. Angew. Chem. Int. Ed. 1998, $37,2580$.

(19) Bar, G. L.; Lloyd-Jones, G. C.; Booker-Milburn, K. I. J. Am. Chem. Soc. 2005, 127, 7308.

(20) Du, H.; Zhao, B.; Shi, Y.J. Am. Chem. Soc. 2007, 129, 762.

(21) Zhu, Y.; Cornwall, R. G.; Du, H.; Zhao, B.; Shi, Y. Acc. Chem. Res. 2014, 47, 3665.

(22) Zhao, B.; Du, H.; Cui, S.; Shi, Y. J. Am. Chem. Soc. 2010, 132, 3523.

(23) Du, H.; Yuan, W.; Zhao, B.; Shi, Y. J. Am. Chem. Soc. 2007, 129, 11688.

(24) Xu, L.; Du, H.; Shi, Y. J. Org. Chem. 2007, 72, 7038.

(25) Xu, L.; Shi, Y.J. Org. Chem. 2008, 73, 749.

(26) (a) Reznichenko, A. L.; Nawara-Hultzsch, A. J.; Hultzsch, K. C. Top. Curr. Chem. 2014, 343, 191. (b) Huang, L.; Arndt, M.; Goossen, K.; Heydt, H.; Goossen, L. J. Chem. Rev. 2015, 115, 259. (c) Coman, S. M.; Parvulescu, V. I. Org. Process Res. Dev. 2015, 19, 1327.

(27) (a) Löber, O.; Kawatsura, M.; Hartwig, J. F. J. Am. Chem. Soc. 2001, 123, 4366. (b) Johns, A. M.; Utsunomiya, M.; Incarvito, C. D.; Hartwig, J. F. J. Am. Chem. Soc. 2006, 128, 1828.

(28) Minami, T.; Okamoto, H.; Ikeda, S.; Tanaka, R.; Ozawa, F.; Yoshifuji, M. Angew. Chem. Int. Ed. 2001, 40, 4501.

(29) Banerjee, D.; Junge, K.; Beller, M. Org. Chem. Front. 2014, 1, 368.

(30) Adamson, N. J.; Hull, E.; Malcolmson, S. J.J. Am. Chem. Soc. 2017, $139,7180$.

(31) Park, S.; Malcolmson, S. J. ACS Catal. 2018, 8, 8468.

(32) (a) Shimizu, Y.; Kanai, M. Tetrahedron Lett. 2014, 55, 3727. (b) Lazreg, F.; Nahra, F.; Cazin, C. S. J. Coord. Chem. Rev. 2015 , 293-294, 48. (c) Semba, K.; Fujihara, T.; Terao, J.; Tsuji, Y. Tetrahedron 2015, 71, 2183. (d) Neeve, E. C.; Geier, S. J.; Mkhalid, I. A.; Westcott, S. A.; Marder, T. B. Chem. Rev. 2016, 116, 9091.
(33) Wu, J. Y.; Moreau, B.; Ritter, T. J. Am. Chem. Soc. 2009, 131, 12915.

(34) (a) Sasaki, Y.; Zhong, C.; Sawamura, M.; Ito, H. J. Am. Chem. Soc. 2010, 132, 1226. (b) Semba, K.; Shinomiya, M.; Fujihara, T.; Terao, J.; Tsuji, Y. Chem. Eur. J. 2013, 19, 7125. (c) Li, X.; Meng, F.; Torker, S.; Shi, Y.; Hoveyda, A. H. Angew. Chem. Int. Ed. 2016, 55, 9997. (d) Jiang, L.; Cao, P.; Wang, M.; Chen, B.; Wang, B.; Liao, J. Angew. Chem. Int. Ed. 2016, 55, 13854. (e) Sardini, S. R.; Brown, M. K. J. Am. Chem. Soc. 2017, 139, 9823. (f) Smith, K. B.; Huang, Y.; Brown, M. K. Angew. Chem. Int. Ed. 2018, 57, 6146.

(35) Fiorito, D.; Mazet, C. ACS Catal. 2018, 8, 9382.

(36) Satoh, M.; Nomoto, Y.; Miyaura, N.; Suzuki, A. Tetrahedron Lett. 1989, 30, 3789.

(37) Tao, Z.-L.; Adili, A.; Shen, H.-C.; Han, Z.-Y.; Gong, L.-Z. Angew. Chem. Int. Ed. 2016, 55, 4322.

(38) (a) Shen, H.-C.; Wang, P.-S.; Tao, Z.-L.; Han, Z.-Y.; Gong, L.-Z. Adv. Synth. Catal. 2017, 359, 2383. (b) Zhang, Z.-J.; Tao, Z.-L.; Arafate, A.; Gong, L.-Z. Acta Chim. Sinica 2017, 75, 1196.

(39) (a) Uno, M.; Takahashi, T.; Takahashi, S. J. Chem. Soc., Chem. Commun. 1987, 785. (b) Uno, M.; Takahashi, T.; Takahashi, S. J. Chem. Soc., Perkin Trans. 1 1990, 647.

(40) Ohshima, T.; Kagechika, K.; Adachi, M.; Sodeoka, M.; Shibasaki, M. J. Am. Chem. Soc. 1996, 118, 7108.

(41) Larock, R. C.; Fried, C. A. J. Am. Chem. Soc. 1990, 112, 5882.

(42) Larock, R. C.; Berriospena, N. G.; Fried, C. A.; Yum, E. K.; Tu, C.; Leong, W. J. Org. Chem. 1993, 58, 4509.

(43) Wu, X.; Chen, S. S.; Zhang, L.; Wang, H. J.; Gong, L. Z. Chem. Commun. 2018, 9595.

(44) Liao, L.; Jana, R.; Urkalan, K. B.; Sigman, M. S. J. Am. Chem. Soc. 2011, 133, 5784 .

(45) McCammant, M. S.; Sigman, M. S. Chem. Sci. 2015, 6, 1355.

(46) Xu, L.; Zhang, X.; McCammant, M. S.; Sigman, M. S.; Wu, Y.-D.; Wiest, O. J. Org. Chem. 2016, 81, 7604.

(47) Stokes, B. J.; Liao, L.; de Andrade, A. M.; Wang, Q.; Sigman, M. S. Org. Lett. 2014, 16, 4666.

(48) Wu, X.; Lin, H. C.; Li, M. L.; Li, L. L.; Han, Z. Y.; Gong, L. Z. J. Am. Chem. Soc. 2015, 137, 13476

(49) Yoshida, M.; Sugimoto, K.; Hara, M. Org. Lett. 2004, 6, 1979.

(50) Luo, L.; Zheng, H.; Liu, J.; Wang, H.; Wang, Y.; Luan, X. Org. Lett. 2016, 18, 2082.

(51) Adamson, N. J.; Wilbur, K. C. E.; Malcolmson, S. J. J. Am. Chem. Soc. 2018, 140, 2761.

(52) Saini, V.; O'Dair, M.; Sigman, M. S. J. Am. Chem. Soc. 2015, 137, 608.

(53) Yeh, M. C. P.; Tsao, W. C.; Tu, L. H. Organometallics 2005, 24, 5909.

(54) Kagechika, K.; Shibasaki, M. J. Org. Chem. 1991, 56, 4093.

(55) Wang, P.-S.; Shen, M.-L.; Gong, L.-Z. Synthesis 2017, 50, 956.

(56) (a) Park, H. S.; Han, J. W.; Shintani, R.; Hayashi, T. Tetrahedron: Asymmetry 2013, 24, 418. (b) Park, H.-S.; Shin, H. M.; Namgung, S.; Han, J. W. Bull. Korean Chem. Soc. 2014, 35, 2613. 